\section{Michigan Technological

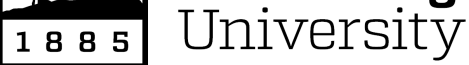

Michigan Technological University Digital Commons @ Michigan Tech

\title{
Open-Source 3-D Printing Technologies for Education: Bringing Additive Manufacturing to the Classroom
}

\author{
Chelsea Schelly \\ Michigan Technological University \\ Gerald C. Anzalone \\ Michigan Technological University \\ Bas Wijnen \\ Michigan Technological University \\ Joshua M. Pearce \\ Michigan Technological University
}

Follow this and additional works at: https://digitalcommons.mtu.edu/materials_fp

\section{Recommended Citation}

C. Schelly, G. Anzalone, B. Wijnen, J. M. Pearce, (2015). Open-Source 3-D Printing Technologies for Education: Bringing Additive Manufacturing to the Classroom. Journal of Visual Languages \& Computing. 28 (2015) 226-237. http://digitalcommons.mtu.edu/materials_fp/47 


\title{
Open-Source 3-D Printing Technologies for Education: Bringing Additive Manufacturing to the Classroom
}

\author{
Chelsea Schelly, ${ }^{\mathrm{a}}$ Gerald Anzalone, ${ }^{\mathrm{b}}$ Bas Wijnen, ${ }^{\mathrm{b}}$ and Joshua M. Pearce ${ }^{\mathrm{b}, \mathrm{c}^{*}}$ \\ a. Department of Social Sciences, Michigan Technological University \\ b. Department of Materials Science and Engineering, Michigan Technological University \\ c. Department of Electrical and Computer Engineering, Michigan Technological University \\ *corresponding author: M \& M Building 601, 1400 Townsend Drive, Houghton, MI 49931. Email: \\ pearce@mtu.edu; Phone: +1 906-487-1466
}

\begin{abstract}
:
Objective: 3-D printing technologies have the potential to improve both Science, Technology, Engineering, and Mathematics (STEM) education and Career and Technical Education (CTE), as well as integrating these two educational emphases and providing opportunities for cross-curriculum engagement. The objective of this study is to investigate the potential of open-source (OS) technologies in an educational setting, given the combination of economic constraints affecting all educational environments and the ability of OS design to profoundly decrease the cost of technological tools and technological innovation.
\end{abstract}

Methods:This paper reports on a 3-day workshop augmented with online instructional and visual tools designed for middle school and high school level educators from a wide array of disciplines (including traditional science, math, and engineering as well as computer, shop, and art) . Teachers ( $\mathrm{n}=22)$ submitted applications to participate in the workshop, the workshop was observed for both evaluation and research, teachers participated in focus groups $(n=2)$ during the workshop in order to discuss their interest in OS 3-D printing technology and its potential role in their classrooms, and teachers completed a voluntary postworkshop survey and responded to follow-up after printers were in the classroom for one year.

Results:During the workshop teachers built 3-D printers using OS technologies that they were then able to take back to their schools and into their classrooms.

Conclusion: Through workshops augmented with online instructional and visual tools designed to provide facilitated yet self-directed engagement with a new, relatively unknown, and relatively complex technology, paired teacher teams were able to successfully build and use RepRap 3-D printers based on OS design in just three days.

Practice: Here, we discuss both what the teachers learned and what we learned from the teachers regarding the potential for educators to construct OS 3-D printing technologies as a tool of empowering and transformative education.

Implications: Open-source 3-D printing technologies have the potential to improve education through a sense of empowerment resulting from active participation, as well as through cross-curriculum engagement.

Keywords: 3-D printing; open-source hardware; STEM education; transformative education; teacher workshop; teacher education

\section{Introduction}

Science, Technology, Engineering, and Mathematics (STEM) education is widely regarded as critical for continued economic competitiveness of any nation because of the direct ties to innovation, economic growth, and productivity [1,2]. Yet there is a persistent concern that neither the quantity nor the 
quality of STEM workers is adequate for the U.S. to compete successfully in the global economy. Despite a protracted period of high unemployment, about 4 million jobs go unfilled in the U.S. due to inadequate numbers of college graduates in STEM-related disciplines [3]. Largely due to the hardware necessary to provide laboratory training, STEM education costs more than most traditional classroom instruction, and as the combination of 1) administrative percentages of educational budgets have increased; 2) proprietary educational materials and lab supplies costs have exploded, and 3) educational budgets have generally diminished, all education is being underfunded and hands-on STEM-related education in particular has been decimated [4].

To reduce costs while catalyzing innovation, open-source (OS) methodologies, which have been so successful in software [5-7], have been applied to educational technologies, tools, and processes [8-10]. The OS concept is important for the public education setting in multiple ways. One area where there is a clear opportunity to improve STEM education while radically reducing costs is to use OS 3-D printers (OS3DP), called RepRaps because they are self-REPlicating RAPid prototypers [11]. RepRaps use a manufacturing method known as fused deposition modeling (FDM) to build physical objects from 3-D computer models using plastics such as PLA. These OS3DPs have already been shown to provide scientific labs substantial economic savings by customizing both simple and advanced scientific equipment [12-14]. For example, to outfit a high school teaching laboratory with 30 optics setups costs less than $\$ 500$ using the OS optics approach, compared to $\$ 15,000$ for commercial versions [15].

Lower-cost and more user-friendly lab equipment is only the beginning of the benefits of using OS3DP in education. OS3DP can be used to fabricate customized physical objects quickly, which can be useful in every academic discipline. These technologies can be used to enhance learning and participation in a robotics class [16], but can also be used for art design and even the development of innovative courses, like an engineering course based on the designs of Leonardo da Vinci [17]. For scholars interested in the potential of OS3DP in the classroom [17,18], their ability to contribute to a wide range of curricula, contents, and contexts makes them appealing for pervasive, ubiquitous adoption.

Of particular interest is the ability for empowering student-driven learning. There is incredible value in students learning how to design and manufacture in a self-driven, empowering educational setting [8]. OS3DP have been used to empower college students [8] and adults [9] to participate in hands-on learning through design and fabrication of both personally useful and economically gainful objects. Previous work by others interested in OS3DP $[8,9,18]$ suggests that learners are most engaged when they are able to actually do something (rather than just reading about it). Students that are empowered through independent engagement with the educational environment are more likely to be active participants [19,20], and self-directed active participation in turn fosters student empowerment [21-23].

Furthermore, OS3DP technologies can contribute to a transformative educational experience among teachers and students alike. Educators can themselves become students during a workshop intended to teach them something new. During this training workshop, educators experienced a transformation of understandings related to the potential of OS3DP for themselves, their classrooms, and broader social relations as well as experiencing a transformation of themselves [24,25] from passive participants to active makers of practical, everyday tools.

In order to facilitate making this educational potential a reality, 22 middle school and high school teachers from a wide array of disciplines (including traditional science, math, and engineering classrooms as well as computer, shop, and art classes) participated in a workshop on building, operating, and troubleshooting OS3DPs (specifically, MOST RepRap printers) for their classrooms. The MOST RepRap printers cost \$550 in parts, of which about half are printed on the printers themselves. As described below, the workshop design was based on self-directed learning, with online instructional and visual tools as well as facilitators available to assist teachers. The workshop was also designed to introduce teachers to research on the economic, environmental, and social potential of OS3DP technologies as well as providing time for teachers to experiment with using the printers to print designs they could select, modify, or create themselves.

The study of this workshop investigated 1 ) the ability of non-experts to build relatively sophisticated 3-D printers relying largely on an OS wiki instructional and digital visual representations of components in a condensed time period, 2) the perceptions of OS3DP among high school educators, and 3) how high school educators understand and articulate the potential of OS3DP technology in their classrooms. This paper examines how teachers participating in the workshop experienced transformation, seeing themselves anew as empowered and active creators of knowledge and materials and recognizing the 
potential of OS3DP for similarly transformative learning among their students. We argue that OS3DP is transformative and empowering in an educational setting; we observed firsthand its effect of teachers, and believe it may bring transformative educational experiences into the traditional classroom by empowering students to be active creators rather than passive consumers of both knowledge and materials, transforming their perceptions of themselves and their abilities through active, participatory education.

\section{Study Methods}

During a 3 and 1/2-day educational and training workshop, educators from across one U.S. state (Michigan) were hosted on a university campus (Michigan Technological University) in order to learn about and construct their own OS3DP. Twelve two-teacher teams (24 teachers, total) initially applied and were slated to participate in the event, but last minute changes in employment led to two teams being short a member. Stand-ins from university staff and program affiliates stepped in to assist, so that 22 teachers in 12 teams completed the workshop, with most (10) teams comprised of two teachers from the same school who constructed printers that they took back to their schools and into their classrooms, and two improvisational teams devised so that individual teachers could still attend and work with a partner, although not a fellow teacher from the same school. A trained social scientist observed the workshop, conducted focus groups with the teachers during the workshop, and analyzed the material provided in workshop applications as well as a post-workshop survey to assess the workshop experience. This research was intended to improve the workshop design for future workshops, explore the potential for developing a scalable online workshop, and examine the meanings teachers associated with OS3DP technology as well as how they understand their potential for the educational setting.

\subsection{RepRap Workshop Design}

Michigan Tech Open Sustainability Technology Laboratory (MOST) hosted the workshop while the Square One Educational Network and GM, both organizations that are interested in supporting STEM education in the state of Michigan, provided necessary funding. The Square One Educational Network aided in recruitment, and most of the teachers attending had participated in other Square One workshops to improve the STEM opportunities they are able to offer students. Food and beverages were provided for breakfast and lunch; the workshop schedule is summarized in Table 1.

Workshop attendees arrived on campus the night before the workshop began to welcome them and introduce them to the workspace. Expectations for the event were also set during this initial meeting; all attendees were informed that this was the first such event of its kind and that they were all pioneers and therefore likely to experience some frustration as they encountered deficiencies in the build process and overall program. Attendees were also given the majority of the tools required for construction, including printed tools that required minor assembly before arriving the next day. Students and faculty from the MOST lab worked together to develop a facilitated self-paced program. Due to the nature of the build process and the tight time line, the schedule was milestone-driven, meaning all printers had to be at the same level of completion at the end of each build day (see Table 1 and Figures 1-3). The program was based upon a detailed written and pictorial online instructional that alone is sufficient for an intrepid tinkerer to complete a build. Four roaming facilitators were available during the workshop build days to assure that each team was able to overcome difficulties and reach the daily milestones. Time lines were estimated based on a beta-test of one team prior to the workshop, and the varying level of skill meant that some teams met their milestones before others, although all teams had successful builds by the beginning of day 3. On the last day of the workshop, teacher teams were given the opportunity to print designs of their choosing; they learned about how to modify existing designs from an online repository and how create their own.

Appropedia.org, a wiki website for collaborative solutions in sustainability, poverty reduction and international development with a particular focus on appropriate technology, hosted the online workshop instructional [26]. Due to the potential to reduce environmental impact [27] and drive self-directed sustainable development with OS3DP technology, Appropedia supports RepRap development [28]. The online documentation begins with a primer meant to introduce teachers to the vocabulary of OS3DP and provide them with a basic understanding of the functioning of the mechanical and electrical components of 
the machine and software that drives it [29]. The MOST RepRap printer components were divided up by functional units. Printed parts, which make up more than half of the printer, were supplied based on a colorcoded scheme as shown in Figure 4.

The MOST Printer is a derivative of the Prusa Mendel RepRap printer incorporating some design changes to facilitate building and minimize cost. All of the designs are open-source and freely available online. While the build process for this printer can be challenging, it has the advantage of being a widely used, mature and well supported design. It is a Cartesian printer. This means that it uses the same coordinate system that high school students are familiar with when using Cartesian graphs to plot a point in 3-D space by using $\mathrm{x}, \mathrm{y}$, and $\mathrm{z}$ coordinates. The Mendel RepRap has distinct $\mathrm{x}, \mathrm{y}$ and $\mathrm{z}$ axes, making it easier to explain kinematics and therefore easier to understand how the machine functions and is controlled (e.g. if a straight wall is printed in the $\mathrm{x}$-axis only the $\mathrm{x}$-axis moves). This is in contrast to a delta-style RepRap where if a straight line is printed all three stepper motors must move.Rather than using simple Cartesian geometry to calculate where the print-nozzle should go, delta printers estimate the head position using moderately complex and non-intuitive trigonometric functions.

To maximize the efficiency as well as the take-home benefit of the workshop, the build instructions were broken into two streams (see Table 2). This ensured that each member of each teacher team was continuously engaged with the build process (see Table 2). This team approach also gave teachers an immediate network of peer support provision after the printers were deployed in their schools.

Teacher teams worked in pairs to complete the printer build.

Rather than rely on extremely detailed and long building instructions written in OS3DP jargon, as are many other RepRap documentation tools [30], this project used a combination of: 1) large, high quality digital photographs of completed sections so that builders would know what their goal was at each stage (as shown in Figure 5a), 2) animations showing the 3-D view of complex parts (as shown in Figure 5b and c), 3) generous images of each stage with concise clear documentation (see Figure 5d), and 4) short presentations and demonstrations for all the stages of the open-source software tool chain: firmware, OpenSCAD for design, slicing, and printer hosting software.

It should be pointed out here that all of the software used was free and open source software, which is available to all the teachers to take back to their schools free of any charge and be installed on as many computers as needed. It is also important to bring specific attention to OpenSCAD, which is a free and open source script based computer aided design package. OpenSCAD was the 3-D solid modeling software that was part of the teacher training, but also available for students to download (openscad.org) and use at home. Using parametric variables that automatically manipulate the entire part to enable simple modifications without the need for knowledge in 3-D modeling. OpenSCAD is used by writing code to describe the geometric specifications of the required object by using primitive shapes (e.g. spheres, cubes, cylinders), complex polygons, and 2-D/3-D extrusion commands. The simple use of OpenSCAD can be taught in under 30 minutes, although more complex functions have a steeper learning curve. As users can immediately see the results of their geometric designs, OpenSCAD is a good way to teach students geometry and coding. Despite the relative ease of use OpenSCAD is a powerful solid modeling program and was used to design all of the components in the 3-D printers that were printed. Finally, OpenSCAD allows for parametric designs, which is the ability to alter a design to specifications by changing the parameters of the geometry of an object (e.g. shapes are written with variables that others can change). This allows changes to be made to the design easily and quickly by simply changing the value of user-defined variables - so once one person designs it, everyone can quickly customize the design for themselves.

Using high-definition photographs of the completed designs effectively enabled the teachers to skip reading steps as the picture provided enough detail to know the placement and orientation of individual components. For example, in Figure 5a, rather than going into detail about the orientation of the idler end it is simply shown. The animations in Figure $5 \mathrm{~b}$ and c enabled the teachers to easily identify the abnormally shaped components from every viewing angle. In addition, each step was photographed in $5 \mathrm{~d}$, which again enabled the teachers to reduce time reading instructions as the component assembly was clarified. Further, several operable printers were brought to the workshop site, and teachers frequently got up to look at these constructed printers in order to further understand the build process or to assess their own work. 
At the beginning of each stage, the facilitators, who had all previously built at least two RepRaps, discussed any complicated building procedures. In the future these discussions can be converted to videos. The build teams would then be left to use the wiki instructions to build that stage. Four facilitators for the 22 teacher-students circulated in the room and assisted the builders with problems. Deficiencies in the wiki instructions (e.g. unclear instructions) were immediately fixed either by the facilitators or, importantly, by the builders themselves. The fixes from the builders were in general of high quality as they were providing answers to problems that they had just had themselves. For odd or complex build steps that were not easily reduced to images, YouTube videos were provided; for example, the Appropedia site included a video on how to braid wires to improve wire management. Individual teachers had different difficulties with different parts of the build. For example, how to adjust a specific screw in a difficult location. These smaller problems are not overly predictable and in general the teachers could overcome them with time. Having facilitators on hand sped up progress and decreased frustration.

\subsection{Data and Analysis}

The data for this paper come from several different sources. Each teacher team submitted an application for participation in the workshop ( $\mathrm{n}=12$ applications), and each teacher was asked to complete a post-workshop online survey $(n=14)$; these files were analyzed for content. A social science researcher observed the workshop for the purposes of both research and evaluation; field notes were taken on site throughout every day of the workshop. In addition, the teachers participated in a focus group during the workshop. Focus groups are essentially group interviews, where a group of relatively homogeneous participants (in this case, educators participating in the workshop) are asked direct but open-ended questions for the purposes of analysis [31]. A total of two focus groups were conducted. The first focus group took place on the second day of the workshop and included nine participants; the second took place on the third day of the workshop and included 11 participants. During these focus groups, teachers were asked about their motivation for participating in their workshop, their evaluation of the experience, and their future plans for using the printer. These conversations intentionally involved discussions about the potential for OS3DP in an educational setting, based on their specific ideas, experiences, and expectations. Both focus groups were recorded and later transcribed for analysis. There were three main aims in developing a research design that allowed for systematic observation and analysis of this workshop. First, we are interested in improving and scaling the workshop instructional so that more teachers can benefit by building OS3DPs in the future. Second, we are interested in understanding the construction of meanings assigned to OS3DP technology, as it is currently an ambiguously defined and newly emerging technological object [32, 33]. Third, we aim to understand how OS3DP can contribute to STEM and CTE education in innovative and meaningful ways. It is this third aim that we focus on in the presentation and discussion of results below.

\section{Results}

All 11 paired teacher teams successfully constructed and configured their printers and were successfully printing objects by the end of the workshop (See Figure 6) with only minor interventions from facilitators. Not only were the teachers successful in building their printers, and printing with them; they also experienced the empowering and transformative learning that they described as possible among students with the help of OS3DP. Teachers were active participants in the creation of both knowledge and objects, communicating with and learning from each other, throughout the workshop.

In addition to experiencing a transformative in their sense of self, their ideas about the potential of OS3DP for transformative education and social relevance also changed through their participation in the workshop. The workshop setting provided an opportunity for teachers to engage with university scholars interested in the social implications and social potentials of OS3DP, related to the environmental, economic and social benefits of appropriate technologies that you can design, make, and repair yourself as well as to the socially beneficial implications of OS design. Through their own transformative experience, teachers learned about and talked about why this technology will benefit students. They discussed how OS3DP technologies can: 1) integrate STEM, CTE and other class subjects through cross-curriculum education, 2) empower students through active learning, 3) get students who are relatively non-involved, because of 
either boredom or perceptions of non-relevance, to engage, and 4) transform educational processes so that students are makers and creators rather than passive consumers of both knowledge and products.

\subsection{A Transformative Educational Process for Teachers}

This initial workshop was a success, in that each teacher team was able to construct an operating RepRap printer and use that printer to create physical objects. Teachers also positively rated the workshop experience in their post-workshop survey responses. Eighty-five percent said that the "facilitated self-paced instruction method" was either "extremely" or "very" effective. When asked: "Did you feel that you were provided with ideas and curriculum that can be seen as relevant to your high school or middle school standards and benchmarks? In other words, is this going to help you teach what you already have to teach?” - only two out of 14 said they were still unsure how to tie it in to required teaching curriculum. During the workshop, teachers heard brief presentations from academic scholars interested in the social consequences of OS3DP, from the economic savings [34], to environmental benefits such as distributed recycling [35, 36], to projects intending to bring appropriate technologies to economically disadvantaged developing nations [28]. Teachers were also able to have informal conversations with professors and graduate students (the workshop facilitators) interested in the socially transformative potential of OS3DP, a technology that allows you to design, make, and repair things yourself and then share those designs with others for continuous community input and improvement. In the post-workshop survey, teachers were most enthusiastic about the "content" of the workshop, with 100\% saying it was "very good" (categories also asked about included the workshop location, kit materials, and instruction). All survey respondents also said that they found the speakers "prepared, interesting, and knowledgeable." In focus groups and in comments on the post-workshop surveys, teachers discussed the value of cost-effectiveness in not only the printers, but also the materials for printing and the resulting printed outputs, especially in public school settings facing increasing budget pressures. They also discussed how the workshop had introduced them to some of the economic and environmental consequences of OS desktop-scale manufacturing and production.

During a focus group conversation, one teacher said, "I like the aspect of the machine that can duplicate itself. And the open-source thing, without patents. I think that's a way of the future that's amazing to me, that people will forego taking a patent out, locking down the technology for themselves, instead take it and disseminate it for all culture, you know, developing cultures, whatever.” In the other focus group, a different teacher said, "This workshop really showed me how much copyrights and patents will be an issue with this technology. I heard a story of someone making models and they open-sourced them.... The copyright and patent system is a broken system. This technology will hopefully push reform. Technology has gone forward, but laws and society have to catch up.” For teachers, the OS dimension and the RepRap's ability to duplicate itself were especially key in an educational setting, where OS design can help keep costs low and can encourage collaboration and dialogue among students, and where duplicability means that they can return to their schools and potentially make more RepRap printers with the involvement of students. As one teacher put it, "From our district, we have gotten nothing from them for years and years and years, and you ask, and there's just no money for it, so this was an opportunity to bring some really cool technology to the kids.” A physics teacher put it this way: "Now I'm thinking about it, I also want to make some parts for my physics lab. I have a very, very limited budget, so if I can replace some of the things I break every year, for pennies... on the dollar, instead of having to go out and shop and buy and beg for money. Cause that's how you have fun in physics, is breaking things." Considering the practical side of RepRap's self-replicating abilities, one teacher wrote in their application for participation: "The self-replicating nature of the printer will encourage us to raise funds and/or write grants to create additional printers that may be readily used building-wide.”

In the post-workshop survey, 50\% of respondents thought that the wiki instruction manual used during the workshop was a "good starting point with some edits," while only one respondent said it was "perfect” for this project. That is, indeed, the whole purpose and the very value of utilizing an OS wiki for the instructional. The manual should not yet be perfect, because it is only perfected through the participation of many. The teachers were, in fact, contributing to and editing the wiki instructions throughout the workshop, evidence of the empowerment involved in engagement with OS3DP. Now, they can return to their classrooms and continue to improve it as they reflect on their experience building the printer and begin to build printers with students. That is the very value of the OS model. 
The data suggest that the workshop experience changed the participating teachers' perceptions of OS3DP. In the applications to participate in the workshop, four out of 12 teacher teams wrote about using the printers in their robotics class, a technical application that was the most common response of potential usages among applicants. At the start of the first focus group, teachers were joking among themselves about 3-D printers being used to make guns [37]. Yet in the second focus group only one day later, teachers said that workshop participation had changed their perceptions of OS3DP. As one teacher put it, "The biggest thing, for me, I think about it as being helpful for the environment. I mean the impact it could have on the environment could be phenomenal. And that's, that's one of the biggest impacts, that's important to me.” To this, another teacher added, “And the cost thing. I hadn't thought about that at all.” To this, a third said, "Yes, about the cost savings of repairs.” A fourth responded, "I think [the speaker's] presentation really kind of brought a lot to light, like the cost savings, recycling, the uses of it, across the board.” A fifth summarized, "Yes. He really planted a seed there.” In the post-workshop survey, one teacher wrote that, for him, the most positive takeaway was "Seeing current research and applications, like making your own investigative equipment rather than just printing out iPhone covers. Make something that we understand, can fix, and students can do the same.” For teachers, participation in the workshop altered their understandings of OS3DP and transformed their perceptions of themselves as makers and creators of environmentally, economically, and socially significant material products that they can share with students in their classrooms. Teachers themselves experienced a sense of empowerment through their successful participation in the construction of a printer and their initial experimentation with design and printing mechanics. As discussed below, teachers participating in the workshop believed that their students would be empowered by the ability to design, build, and create unique physical objects using OS3DP. Thus, we witnessed among teachers a sense of engagement and empowerment, and an experience of transformation, similar to what they believed students would experience by working with OS3DP. In the post-workshop survey, 10 out of 14 respondents said that the proud sense of accomplishment they experienced (often summarized in phrases like "We built it!!!!”) was the "most positive takeaway” from the workshop experience; one participant aptly described the most positive takeaway as a newfound "can do attitude." Thus, teachers experienced the same sense of transformation that they expected to witness among students when working with OS3DP.

\subsection{The Transformative Educational Potential for Students}

Teachers specifically discussed four ways in which OS3DP could improve the educational experience by providing students with an empowering and transformative opportunity. They discussed the potential for using OS3DP to connect CTE and STEM education and to engage in cross-curriculum collaboration. They talked about how students may be inspired to actively participate and work through conceptual or abstract problems because of the resulting tangible, physical reward associated with designing and printing using OS3DP. They talked about OS3DP as beneficial for getting non-involved students engaged and/or providing an opportunity for additional challenges for bright, driven, or what they called "gifted" students who they described as often bored in a typical classroom. Finally, they discussed the empowerment that can come from making things, why it's empowering to make things, and how OS3DP can offer a transformative educational experience as students begin to see themselves - just as teachers did - as creators and makers rather than passive consumers of both knowledge and products.

In a workshop application, one participating teacher stated, “Our district has a technology plan to move forward and integrate technology in all aspects of learning.” The teacher felt that bringing a RepRap printer back to school could help address this plan. In a second workshop application, an administrator stated in a letter of support that participation in the workshop could contribute to "the infusion of STEM initiative across all curriculum.” During the workshop, teachers talked about how OS3DP could be used to benefit a variety of school subjects, and even contribute to cross-curriculum education. One participant said there are "possibilities for crossover in classes, math and science and beyond. What has to happen is allowing the unintended possibilities.” This teacher also talked about the idea of having a 3-D printing club at school, to allow students to self-direct their experiences with it. Another teacher said that there might be a perception that "this is just an engineering thing, or just manufacturing." To this, he added: "No, you name it, you can use it in the arts, you can use it in whatever you want to use it in.” In a workshop application, another teacher wrote, "The printer has almost unlimited potential to make our departmental teaching units become more hands-on and student oriented.” Teachers talked about possibilities from 
designs for art class to model fossils in biology, and even interdisciplinary engagement in thinking about appropriate technology designs and talking about the geography and social studies lessons that would necessarily accompany such a project.

Teachers also talked about how OS3DP can connect CTE and STEM education. As one teacher said, "kids learn in a variety of ways.... This is for the kids that like working with their hands, right, and for them they're having fun, and everyone learns a different way." To this another teacher responded, "See I think, the 3-D printer opens the door for the kid, maybe the kid that doesn't know how to... draw something up really pretty or whatever and design it.... [That kid could] give it to another person, and they can do the solid modeling of it, and they can go ahead and print the physical object or something. It just, for, it allows some of the students to get involved." To this, a third teacher added, "It really is that integration of CTE and STEM.” For these teachers, OS3DP could encourage students to engage with both abstract thought and practical design, because, as they see it, you need both. One workshop application included an administrative letter of support that stated: "Since our school is located in a rural setting, we are excited about the chance to show to our students innovative technical applications used in industry. We strive to excite and engage them in the fields of science, math, and engineering by highlighting 'real world' situations such as your 3-D prototype printer.”

Teachers believed that the ability to create a physical object with 'real world' application out of an abstract design would motivate students to engage with 3-D printing technology. One teacher talked about bringing a 3-D printer (that he did not get to keep) into his classroom for a demonstration, and he said, "just seeing the kids faces you know, imagination into physical object, it was just powerful, it's hard to explain, it just zapped them, they were all in.” In an administrative letter of support included with a workshop application, one administrator wrote: "Through my own observations I have seen the excitement and enthusiasm this hands-on science offering (a Marine Robotics class) has brought to our students.... The enjoyment on the faces of our students as they collaboratively design, problem solve, build and program the robots is priceless.” The teachers expressed, in various ways, that when students are excited about something and then are given the opportunity to actually apply that excitement to the creation of a physical object, excitement becomes empowerment, which is its own internal motivator. One teacher specifically described it this way:

When you do stuff like this, students get so excited. Then typically when you go back, you try to learn some stuff about electricity, and there's math involved, and typically they will shut down. But when they see application, it makes more sense, and it's like, 'Hey, I'm gonna do this stuff, I've gotta learn more so I can do more of this stuff, and look into it.' It's kind of an internal motivator, I look at it as. It's more authentic when they do it, and that way, when they hit something abstract, they have something to relate it to, it's more tangible.

The popularity of this technology with the students can have unintended consequences; a high school student at one of the beta-test schools for this workshop was caught attempting to break into school in the middle of the night, not to vandalize but to get extra time on the RepRap to improve his self-directed class project [38]. This level of student enthusiasm for extra schoolwork is generally uncommon.

For the teachers who participated in this workshop, the empowerment that comes from the ability to create a tangible physical object based on a student's own personal design is especially important for particular groups of students: those who are not easily engaged with learning in a traditional classroom, and those who are "gifted" and/or "bored." As one teacher put it, "Gifted kids need something more to do." Another said, "I think there's a large group of students that are bored. They don't see anything as really challenging, so they don't participate a lot, and I think this might be something that they would springboard to, because it's so different.” One teacher, who built a RepRap printer as part of the pilot program for this workshop and has had the printer in his classroom for six months, recounted a story of a student who has silently participated in his shop class for years. With tears in his eyes, he described how the student got up and went to the printer one day to make something he had designed, and how the student had since transformed into someone conversational, participatory, and engaged.

One of the most significant potentials of OS3DP for an educational setting, according to these teachers, is its ability to contribute to a transformative education in which students recognize their ability to design, create, and make, in contrast to their modern social position as passive consumers of both 
knowledge and products. One administrative letter of support optimistically stated that OS3DP "will help ensure our teachers and students explore new vehicles of teaching and learning by being effective communicators, global citizens, critical/creative thinkers, and self-directed learners.” During a focus group, a teacher said, "I think this gives them a sense of ownership too, whereby, if you give them the opportunity, if you say, 'Ok, I need you to design a keychain,' I need you to design whatever it may be, some simple task, they're gonna get the programming, and it will be their keychain. It will be one of the few things they've actually made in their lives from nothing." To this, another teacher added, "Yeah, it’s that satisfaction of yeah this is my turf, and I can own it."

Teachers were much more specific about the transformative potential of OS3DP. They recognized their own experience of transformation, as being empowered by their ability to create (both by building the printer and by being able to design and print objects), and felt that all students could potentially have a similar experience. Teachers also discussed one particular way to use OS3DP, giving students the ability to design and print replacement parts to repair things. To these teachers, the ability to repair broken objects seemed like an important way to empower students and transform their sense of their own abilities. One teacher said, "We've gotten so far away from that as a society - a Can-Do versus a consumer attitude. How do you fix it? Do you have the confidence to fix it? We use to dig in and fix it. That's the trick to this whole thing, just open the door and just let them.” To this, another teacher added that in most traditional educational settings, "there's a real lack of opportunity for that kind of empowerment, a self-sufficiency of sorts, where kids are learning to fix things." One teacher said that with OS3DP, there's the potential to say, "Ok, if that part's broke, let's reverse engineer it and make a new one.” This use of OS3DP to design parts to fix broken material objects provides a new insight into the potential educational opportunities and applications not commonly mentioned by scholars interested in the technology.

In focus groups during the workshop, participating teachers discussed how OS3DP technologies can help them integrate STEM, CTE and other subjects in student learning, empower active learning, get students who are relatively non-involved to engage, and provide transformative educational opportunities whereby students realize their ability to make and create rather than being merely passive consumers of both knowledge and products. Teachers recognized the workshop as a transformative experience for themselves and discussed the transformative and empowering potentials of OS3DP for their students. After having their printers for one academic year, teachers were again asked for feedback and to share their experiences. The use of the printers varied widely with some schools having not used the printers while others used them even more than planned. For example, at one teacher's small, rural school, the printer has "been running almost continuously," and has been used - as expected - to make many parts by and for the school's robotics team [39]. However, the students have also done demonstrations with the printer [39]; thus, the printer has unexpectedly help student develop oral presentation skills, a clearly beneficial crosscurriculum application. A second teacher shared a new idea, to use the printer to print objects to be sold for school fundraisers, which would benefit school clubs, but has yet to come to fruition. Certainly, there is more work to be done in terms of getting teachers comfortable using the printers and creating a database of relevant curricular applications. These results reiterate that transforming education requires much more than the device itself. Simply putting 3-D printers is schools does not automatically provide a better learning environment or make students into makers and creators. Providing teachers with the training necessary to transform them into makers may make this more likely, but again does not guarantee that students will be transformed into creators rather than passive consumers of knowledge. This study is a first step in a larger educational initiative that will require developing activities and curriculum that fit current standards and are tested across many student populations and evaluated for their effectiveness. Follow up studies can determine how teachers have changed their instruction after the use of open-source 3-D printers and the if the student experiences also change as a result. Finally, future work could include a control group study where 3-D printers alone are introduced to the classroom to investigate the impacts of the technology itself. Yet this does not diminish the centrality of the findings presented here: teachers found their engagement with OS3DP empowering and transformative, and expressed beliefs that the technology could offer students these experiences as well.

\section{Discussion}


Feedback from this initial 3-D printer workshop has been overwhelmingly positive. The workshop program resulted in the successful construction of OS3DP through self-directed facilitated learning; the workshop experience demonstrated the powerful potential and cost effectiveness of freely available OS hardware and software tools. The teacher's comments both during the workshop and on the post-workshop survey indicate that the workshop experience increased their knowledge of and interest in a complex piece of new technology, empowering them in a way that they hope to similarly engage students in their classrooms.

OS3DP have the potential to offer a transformative educational experience. Active engagement rather than passive learning can be an empowering experience [40]. OS3DP offers the additional benefit of allowing users to create material objects through abstract design processes made visual and physical, which has the potential to transform their understanding of themselves as active creators of both knowledge and things. Indeed, reports from some teachers indicate that students are so captivated by the printer that they engage in self-initiated and self-directed design, as discussed above.

These technologies, brought into the classroom, have potential to transform the educational setting. OS3DP can facilitate cross-curriculum engagement as they are used to make artwork and crafts, models of all kinds, and technologies appropriate for particular geographies and societies. Through crosscurriculum collaboration, including the integrating of CTE and STEM education but also considered more broadly through coordination of curricula in multiple disciplines, students can be engaged with other types of knowledge meant to enhance and contextualize their fabrications. Furthermore, OS3DP has the potential to be socially transformative, radically restructuring the organization and scale of production [41,42]. Bringing this technology into the classroom allows teachers and students alike to learn about its potential.

There were limitations in the design and execution of this workshop that can be addressed in the future. The MOST printer is a complex machine comprised of hundreds of parts . While the program developed for the workshop proved to be very effective, the complex and time consuming nature of the build may make it difficult for the RepRap to serve its full potential for re-creation once in the classroom. A simpler design could increase the rate of introduction into classrooms. Potential design candidates fitting this requirement are presently being evaluated. Also, the printer is a metric machine, units that are unfamiliar to many U.S. citizens. Some difficulty was encountered in recognizing the proper sized fastener during the build and a template showing the fasteners in actual size was suggested as a way to make identification easier. As another means of acknowledging the complexity of the build process, the addition of assembly animations showing how individual pieces go together to form a functional unit is planned for the online instructional to augment the existing animations of individual printed parts and photographs of the parts being worked upon

Technological IT issues were encountered with the installation of the necessary software on school-owned and managed computers because of restrictions imposed at the school district level; some completely prohibited installation on some users' machines, bringing progress to a complete stop. One of the five teachers responding one year after the event said that this continues to impede their ability to use their printer. To address this technically it may be possible to provide inexpensive Raspberry Pi Linux computers as part of the printer kits for future workshops. Future events will include more detailed and rigorous pre-installation requirements for attendees, ensuring that the required software is fully installed and functional before the workshop.

Meaningful follow-up with attendees and their students is an essential next step in the process. There are bound to be challenges to incorporating this technology into existing curricula, and understanding how the teachers who attended the workshop use the technology in the classroom along with objective evaluation of those uses is key to formulating effective curricula that utilizes OS3DP. This follow-up is also essential for assessing the potential of the technology in curricula not traditionally STEM-related. OS3DP technology seems a natural fit with STEM disciplines, but there is no clear path to the creation of effective curricula, especially with regards to delivery of Common Core Standards. Future research will improve upon the weaknesses identified during the evaluation of this workshop and its impact. The MOST Laboratory will be working to connect teachers with one another, with graduate students and technical assistants who can offer assistance, and with a developing repository of specific ideas and applications for using OS3DP in the classroom. 


\section{Conclusions}

Through workshops augmented with online instructional and visual tools designed to provide facilitated yet self-directed engagement with a new, relatively unknown, and relatively complex technology, paired teacher teams were able to successfully build and use RepRap 3-D printers based on OS design in just three days. These workshops were designed to bring OS3DP technologies into the classroom. The OS aspect is particularly relevant in the educational setting, as it decreases cost of access as well as encouraging active participation and improvement through real experience with design and fabrication, as was demonstrated by the successful use of an OS wiki instructional for the workshop that teachers themselves were improving during the workshop.

3-D printing technologies based on open-source design have transformative potential in an educational realm. Teachers described how their understandings of these newly emerging technologies evolved via workshop participation, as they learned about their environmental, economic, and social impacts. They also described the sense of empowerment resulting from the experience of making something, in turning a pile of parts into an operable printer and then an abstract design into an actual object. The teachers discussed this transformative potential as an important consequence of getting OS3DP in the classroom, as students themselves may be able to experience a transformation that allows them to see themselves as active creators, makers of objects and their own educational experiences.

\section{Acknowledgements}

The authors would like to acknowledge support from the Square One Education and GM for the workshop. The authors would also like to acknowledge the help of the workshop facilitators D. Oppliger and N. Anzalone and the technical support of S. Feeley and M. Poszywak.

\section{References}

[1] A. P. Carnevale, N. Smith, M. Melton. STEM, 2011. Georgetown

Public Policy Institute, available http://cew.georgetown.edu/STEM/, 2011.

[2] http://www.esa.doc.gov/Reports/stem-good-jobs-now-and-future, accessed September 6, 2013.

[3] National Math and Science Initiative. Increasing the Achievement and Presence of Under-Represented Minorities in STEM Fields. http://nms.org/Portals/0/Docs/whitePaper/NACME\%20white\%20paper.pdf, accessed September 6, 2013.

[4] B. Kelly, The State of STEM and Jobs, US News and World Report, September 12, 2012. http://www.usnews.com/news/articles/2012/09/21/the-state-of-stem-and-jobs, accessed September 6, 2013.

[5] D. W. Bretthauer, Open source software: A history, Information Technology

and Libraries 21 (2002) 3-10.

[6] J.Y. Moon, L. Sproull, Essence of distributed work: The case of the Linux

kernel, First Monday 5 (2000).

http:/firstmonday.org/htbin/cgiwrap/bin/ojs/index.php/fm/article/view/801/710, accessed January 25, 2013.

[7] E. S. Raymond, The cathedral and the bazaar, First Monday 3 (1988).

http://firstmonday.org/htbin/cgiwrap/bin/ojs/index.php/fm/article/view/578/499, accessed January 25, 2013.

[8] N. Gershenfeld, Fab: The Coming Revolution on Your Desktop - From Personal Computers to Personal

Fabrication, New York, Basic Books, 2005.

[9] M. Hatch, The Maker Movement Manifesto, New York, McGraw-Hill, 2014.

[10] H. Lipson, Fabricated: The New World of 3D Printing, Indianapolis, John Wiley \& Sons, 2013.

[11] R. Jones, P. Haufe, E. Sells, P. Iravani, V. Olliver, C. Palmer, A. Bowyer, Reprap- the replicating rapid prototyper, Robotica 29 (2011) 177-191.

[12] J. M. Pearce, Building research equipment with free, open-source hardware, Science 337, 6100 (2012)

1303-1304.

[13] G.C. Anzalone, A.G. Glover, J.M. Pearce, Open-source colorimeter, Sensors

13 (2013) 5338-5346. doi:10.3390/s130405338

[14] J. M. Pearce, Open-Source Lab, 1st Edition: How to Build 
Your Own Hardware and Reduce Research Costs, Elsevier, 2014. ISBN: 9780124104624

[15] C. Zhang, N.C. Anzalone, R.P Faria, J.M. Pearce, Open-source 3D-Printable

optics equipment, PLoS ONE 8(2012) e59840. doi:10.1371/journal.pone.0059840

[16] Rachel Goldman, A. Eguchi, E. Sklar. Using educational robotics to engage inner-city students with technology. In Proceedings of the $6^{\text {th }}$

international conference on Learning sciences, International Society of the Learning

Sciences, 2004, pp. 214-221.

[17] M. Eisenberg. Educational fabrication, in and out of the classroom, in: M. Koehler \& P. Mishra (Eds.), Proceedings of Society for Information Technology \& Teacher Education International Conference. AACE, Chesapeake, VA, 2011, pp. 884-891.

[18] M. Eisenberg, L. Buechley, Pervasive fabrication: Making construction

ubiquitous in education, Journal of Software 3 (2008) 62-68.

[19] C. Schelly, J.E. Cross, W.S. Franzen, P. Hall, S. Reeve, How to go

green: Creating a conservation culture in a public high school through education,

modeling, and communication, J. of Environmental Education 43 (2012) 143-161.

[20] C. Schelly, J.E. Cross, W.S. Franzen, P. Hall, S. Reeve, Reducing

energy consumption and creating a conservation culture in organizations: A case study of

one public school district, Environment and Behavior 43 (2011) 316-343.

[21] W.R. Torbert, Educating toward shared purpose, self-direction and quality work: The theory and practice of liberating structure, J. of Higher Education 49 (1978) 109-135.

[22] M. Knowles, The Modern Practice of Adult Education, Association Press, New York, 1980.

[23] P. Cranton, Self-directed and transformative instructional development, J. of Higher Education 65 (1994) 724-744.

[24] J. Pearce, The Use of self-directed learning to promote active citizenship in science, technology and society classes, Bulletin of Science, Technology and Society 21 (2001) 312-321.

[25] L. Markos, W. McWhinney, Editor’s perspectives: Auspice, J. of Transformative Education 1 (2003)

3-15.

[26] J. M. Pearce, L. Grafman, T. Colledge, R. Legg, Leveraging information technology, social

entrepreneurship and global collaboration for just sustainable development, Proceedings of the 12th Annual National Collegiate Inventors and Innovators Alliance Conference, 2008, pp. 201- 210.

[27] M. Kreiger, J.M. Pearce, Environmental impacts of distributed manufacturing from 3-D Printing of polymer components and products, MRS Online Proceedings Library 1492 (2013), mrsf12-1492-g01-02 doi:10.1557/opl.2013.319. [28] J.M. Pearce, C. Morris Blair, K. J. Laciak, R. Andrews, A. Nosrat, I. Zelenika Zovko, 3-D printing of open source appropriate technologies for self-directed sustainable development, J. of Sustainable Development 3 (2010), 17-29.

[29] See http://www.appropedia.org/MOST_RepRap_Primer.

[30] See, for example, http://reprap.org/wiki/Prusa_Build_Manual, accessed September

6, 2013.

[31] R.A. Krueger, M.A. Casey, Focus Groups: A Practical Guide for Applied

Research, fourth ed., Sage, Thousand Oaks, CA, 2009.

[32] N. Oudshoorn, T. Pinch (Eds.), How Users Matter: The Co-Construction of

Users and Technologies, MIT Press, Cambridge, Mass, 2003.

[33] B. Rappert, The distribution and resolution of the ambiguities of technology, or why bobby can't spray, Social Studies of Science 31 (2001) 557-591.

[34] B.T. Wittbrodt, A.G. Glover, J. Laureto, G.C. Anzalone, D. Oppliger, J.L. Irwin, J.M. Pearce Life-cycle economic analysis of distributed manufacturing with open source 3-D printers, Mechatronics 23 (2013), 713-726.

[35] M. Kreiger, G. C. Anzalone, M. L. Mulder, A. Glover, J. M. Pearce, Distributed recycling of post-consumer plastic waste in rural areas, MRS Online Proceedings Library 1492 (2013), mrsf12-1492-g04-06.

[36] C. Baechler, M. DeVuono, J.M. Pearce, Distributed recycling of waste polymer into RepRap feedstock, Rapid Prototyping Journal 19 (2013) 118-125.

[37] N. Gershenfeld, How to make almost anything, Foreign Affairs Nov/Dec (2012) 43-57.

[38] J. L. Irwin, J.M.Pearce, G. Anzalone, Implementing self-replicating rapid 
prototypers (RepRaps) into a mechanical/manufacturing program, ATMAE 2013

Conference Proceedings Papers - Manufacturing Track, (2013).

[39] See http://dollarbaysoar.blogspot.com/, accessed July 11, 2014.

[40] M. B. Crawford, Shop Class as Soulcraft. New York, Penguin, 2009.

[41] J. Schor, Plentitude: The New Economics of True Wealth. New York, Penguin, 2010.

[42] J. Rifkin, Third Industrial Revolution: How Lateral Power is Transforming Energy, The Economy, and the World. New York, Palgrave Macmillan, 2011.

Table 1. Open-source 3-D Printer Workshop Schedule

\begin{tabular}{|l|l|l|}
\hline Day & AM/PM & Task \\
\hline & PM & $\begin{array}{l}\text { Arrival, welcome, introduction to work space, tools distributed; tools require } \\
\text { some minor assembly (homework) and must be brought back the next day as } \\
\text { they are required for the build. }\end{array}$ \\
\hline 1 & AM & $\begin{array}{l}\text { Introduction to building - what to do and what not to do. Assemble the printer } \\
\text { frame and y-carriage. }\end{array}$ \\
\hline 2 & AM & Assemble x- and y-axis. \\
\hline PM & PM & $\begin{array}{l}\text { Assemble extruder and x-carriage, assemble z-axis, align frame. } \\
\text { firmware. }\end{array}$ \\
\hline 3 & AM & $\begin{array}{l}\text { Commission printer - introduction to Cura, Repetier Host and bed leveling } \\
\text { with first print. }\end{array}$ \\
\hline 4 & AM & $\begin{array}{l}\text { Presentation : 3-D Printing and STEM Education: The Perfect Confluence, } \\
\text { Introduction to OpenSCAD - simple designs. Work on design project. }\end{array}$ \\
\hline & PM & \begin{tabular}{l} 
Complete project and print \\
\hline
\end{tabular} \\
\hline
\end{tabular}


Preprint : Chelsea Schelly, Gerald Anzalone, Bas Wijnen, Joshua M. Pearce, (2015). Open-source 3-D printing Technologies for education: Bringing Additive Manufacturing to the Classroom. Journal of Visual Languages \& Computing. 28 (2015) $226-237$. DOI: 10.1016/j.jvlc.2015.01.004

Table 2. Tandem MOST Prusa Mendel RepRap Build task list.

\begin{tabular}{|l|l|}
\hline & Soldering \\
\hline Y carriage & Frame \\
\hline X axis & Y axis \\
\hline Extruder and X-carriage & Z axis and frame alignment \\
\hline Braid motor wires & Electronics \\
\hline \multicolumn{2}{c}{ Firmware } \\
\hline & Finish the build \\
\hline
\end{tabular}

\section{Figures}

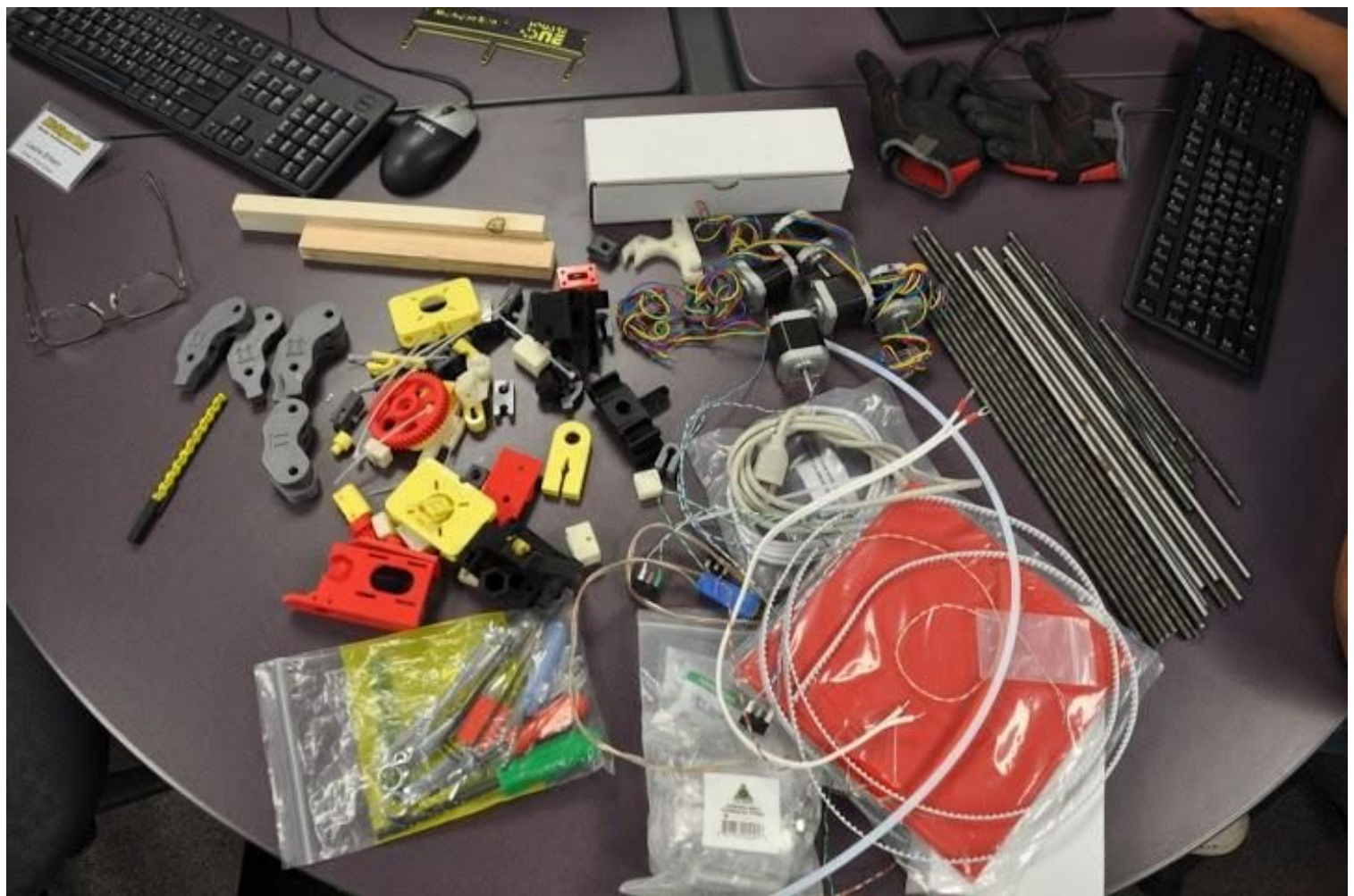

Figure 1: Assembly Kit: The assembly kit was given to each teacher team on the day prior to the workshop. 
Preprint : Chelsea Schelly, Gerald Anzalone, Bas Wijnen, Joshua M. Pearce, (2015). Open-source 3-D printing Technologies for education: Bringing Additive Manufacturing to the Classroom. Journal of Visual Languages \& Computing. 28 (2015) $226-237$. DOI: 10.1016/j.jvlc.2015.01.004

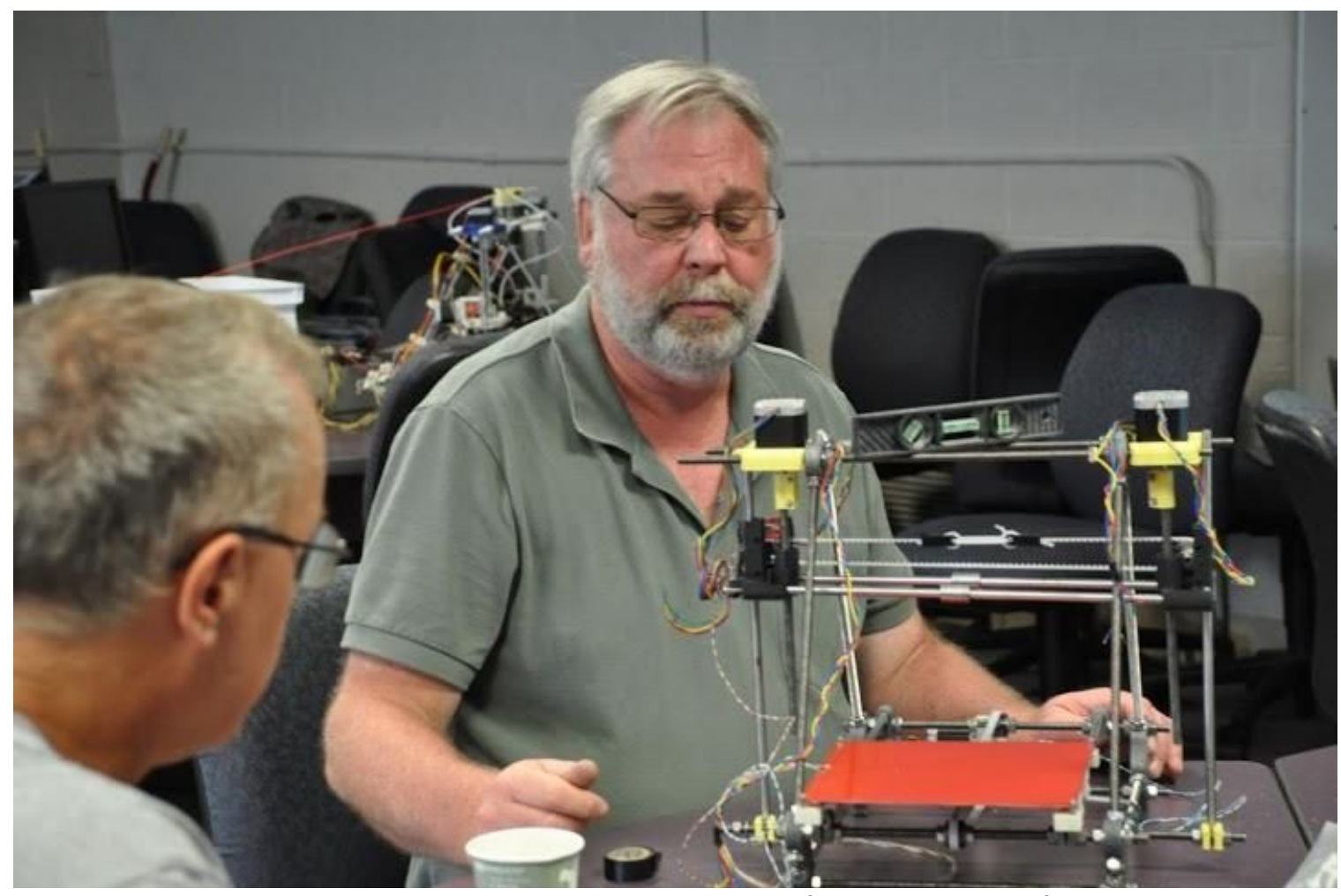

Figure 2: Assembly, Day One: A teacher assembling the printer frame on day one of the workshop.

Figure 3: Assembled Printer, Day Two: A teacher with their assembled printer at the end of day two of the workshop.

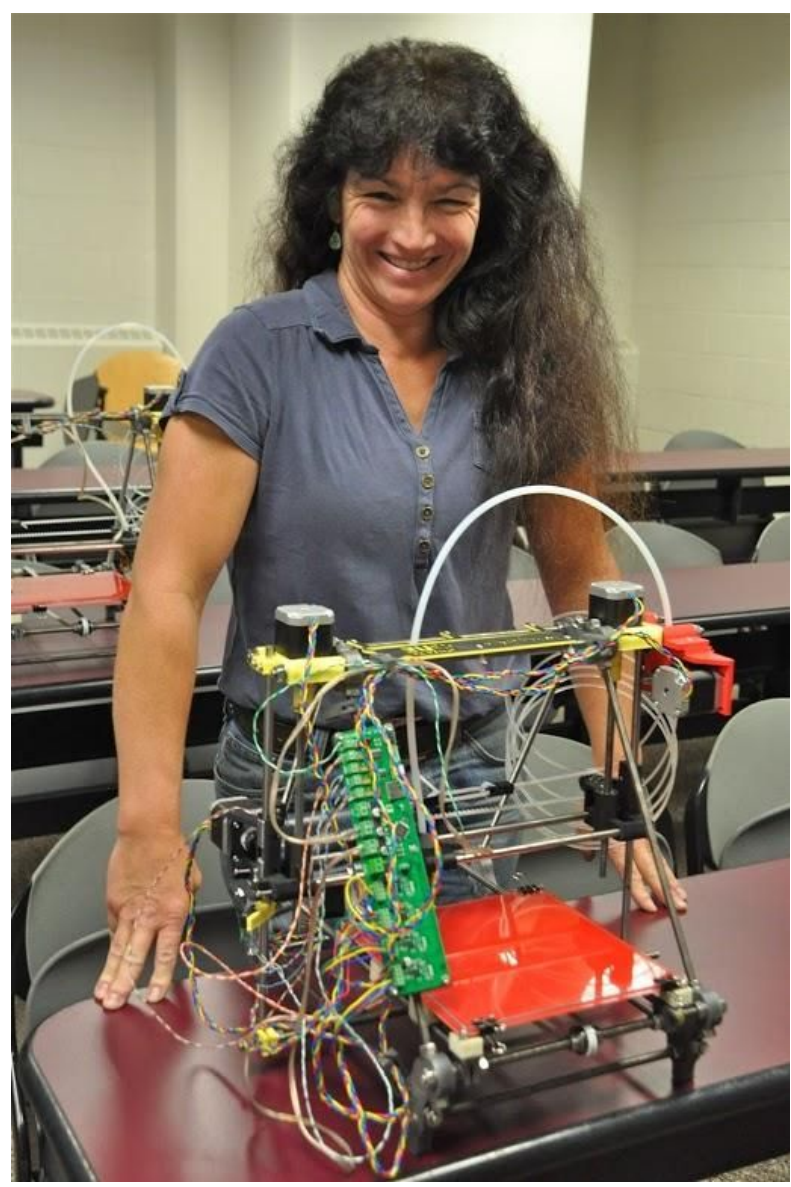


Preprint : Chelsea Schelly, Gerald Anzalone, Bas Wijnen, Joshua M. Pearce, (2015). Open-source 3-D printing Technologies for education: Bringing Additive Manufacturing to the Classroom. Journal of Visual Languages \& Computing. 28 (2015) $226-237$. DOI: 10.1016/j.jvlc.2015.01.004

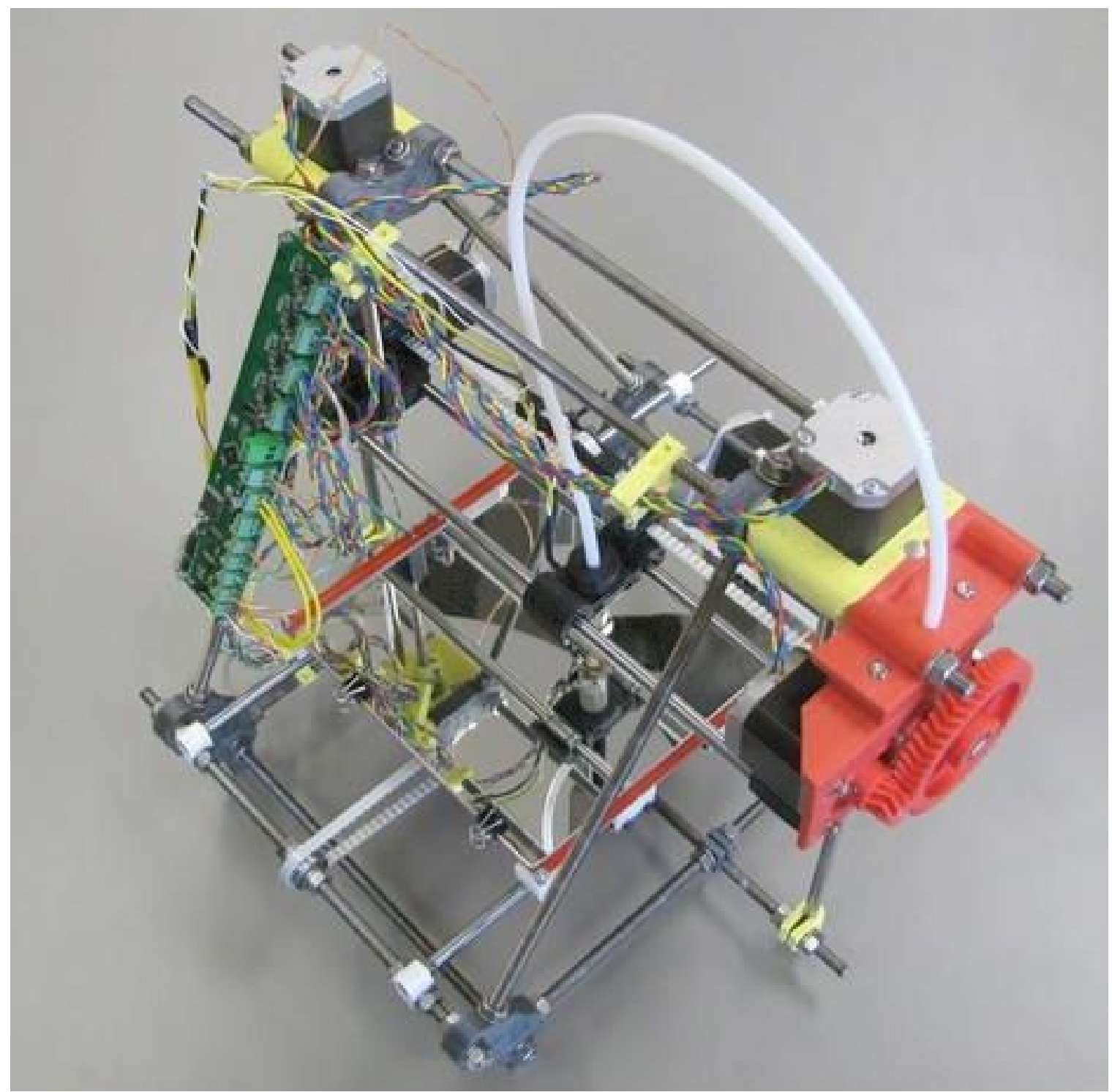

Figure 4: The MOST RepRap Printer, which is color coded for easy assembly both in the physical parts but also in the animated graphics and on the wiki. Key: Silver: Frame (vertexes, rod clamps, wire holders, Melzi board mounts); Black: X-axis (motor and idler ends, X-carriage, belt terminators, end stop holder, 12 tooth T5 pulley); White: Y-axis (motor mount, belt terminators, y-carriage corners and bearing saddles, 12 tooth T5 pulley); Yellow: Z-axis (motor mounts, guide rod clamp, z-motor couplings, bar clamps, end stop holder); Red: Extruder (extruder drive body, idler, gears, extruder drive spacer with Bowden nut trap, extruder drive mount). 
Preprint : Chelsea Schelly, Gerald Anzalone, Bas Wijnen, Joshua M. Pearce, (2015). Open-source 3-D printing Technologies for education: Bringing Additive Manufacturing to the Classroom. Journal of Visual Languages \& Computing. 28 (2015) $226-237$. DOI: 10.1016/j.jvlc.2015.01.004

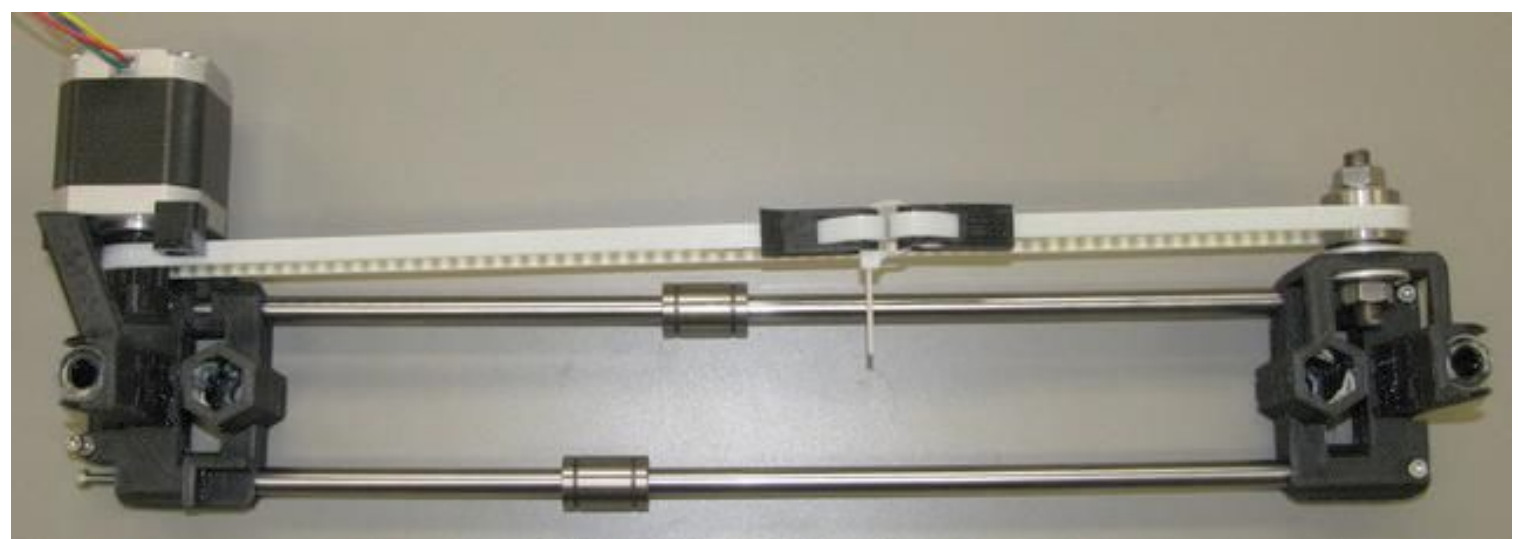

Figure 5a. Detail of a completed X-axis.
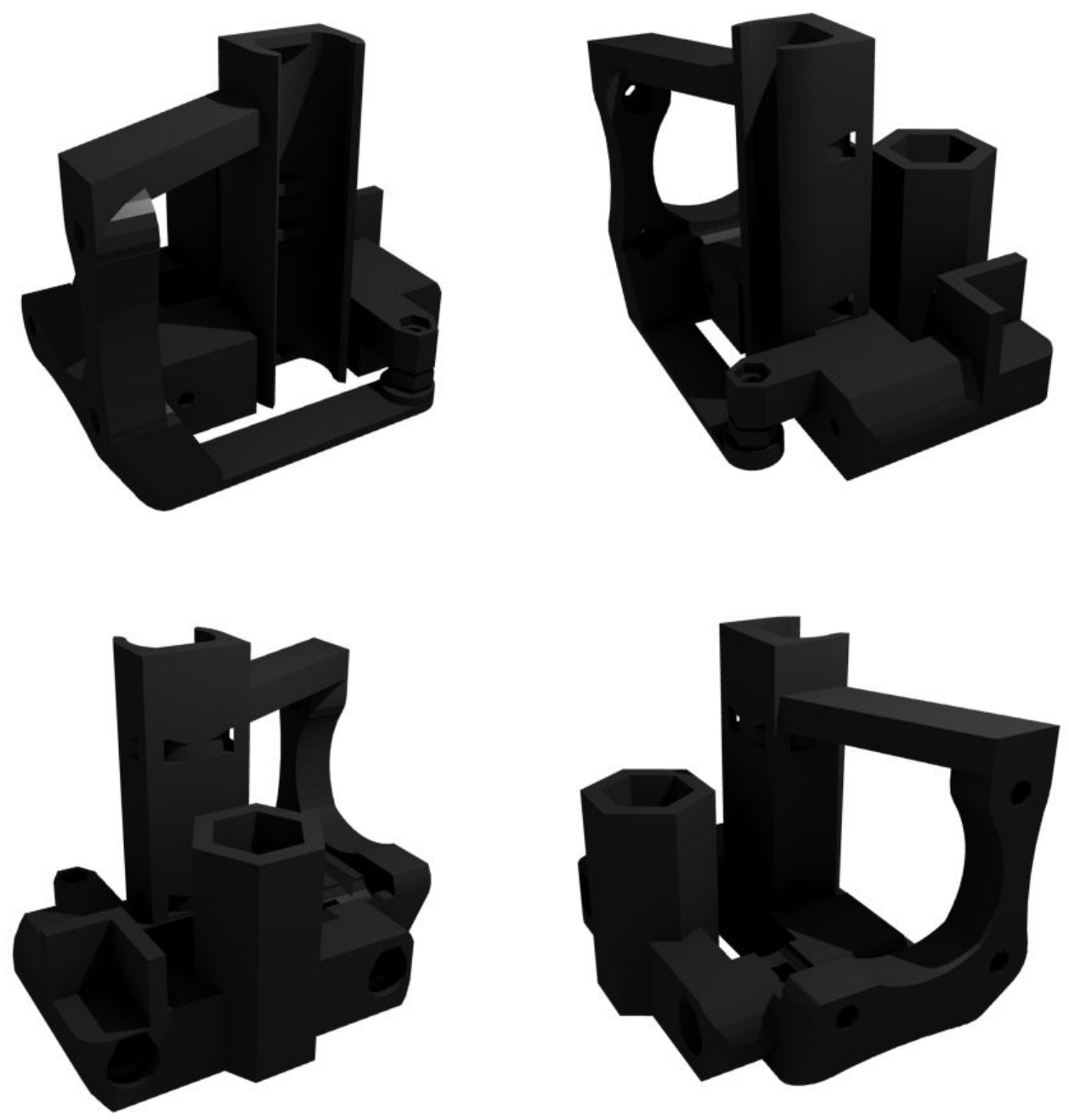

Figure 5b. Example of animated GIF images showing complex 3-D printed parts of the X-axis from multiple angles. 
Preprint : Chelsea Schelly, Gerald Anzalone, Bas Wijnen, Joshua M. Pearce, (2015). Open-source 3-D printing Technologies for education: Bringing Additive Manufacturing to the Classroom. Journal of Visual Languages \& Computing. 28 (2015) $226-237$. DOI: 10.1016/j.jvlc.2015.01.004
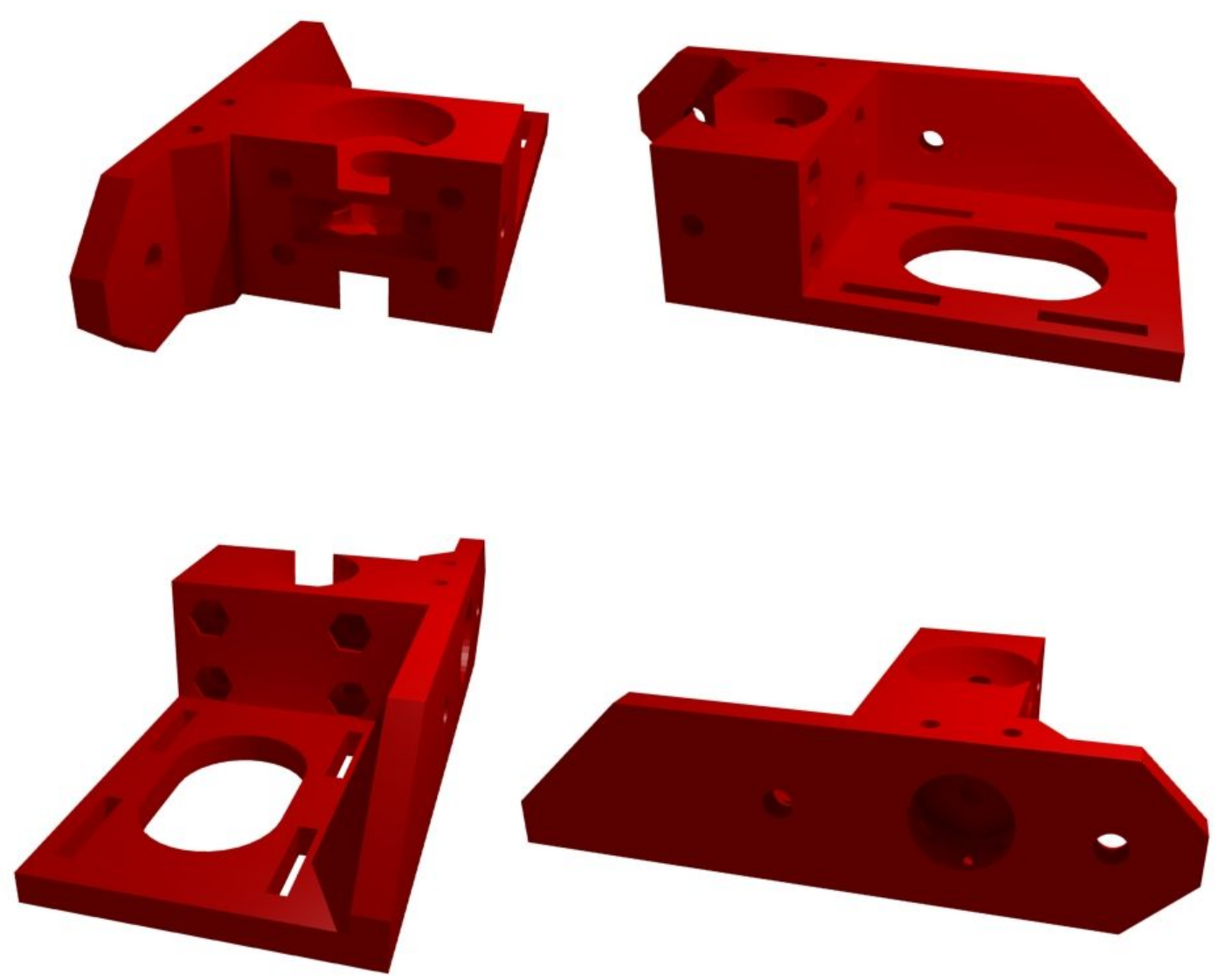

Figure 5c. Example of animated GIF images showing complex 3-D printed parts of the extruder body from multiple angles.

The animations showing the 3D view of complex parts were made by loading the models of the parts (that are also used for printing them) into Blender, an open-source animation program, and instructing it to rotate them and record a video of this. This video was then converted to an animated (rotating) GIF for integration into the web instructions. 
Preprint : Chelsea Schelly, Gerald Anzalone, Bas Wijnen, Joshua M. Pearce, (2015). Open-source 3-D printing Technologies for education: Bringing Additive Manufacturing to the Classroom. Journal of Visual Languages \& Computing. 28 (2015) $226-237$. DOI: 10.1016/j.jvlc.2015.01.004

22. Push the motor towards the large gear moving the small gear as necessary to mesh the gears' teeth. Once the teeth mesh well, tighten the set screw in the small gear and tighten the exłosed motor mounting screws.

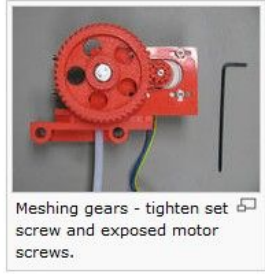

23. Remove the hobbed bolt and large gear to expose the remaining motor mounting screws and tighten them. Replace the large gear and hobbed bolt insuring that all the spacer washers are in place. Recheck hob position relative to filament path.

24. Push the assembled idler onto the four idler mounting screws and ensure that the idler moves relatively freely on the screws. On each of the screws, place an M4 washer followed by a $3 / 8^{\prime \prime} \times 9 / 32^{\prime \prime}$ spring then another washer and finally an M4 nut.

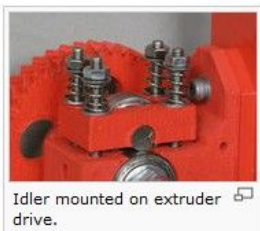

1.5 Return to Main Page

MOST_HS_RepRap_parallel_build_overview

Category: MOST RepRap build

Figure 5d. Instructions for finishing the extruder build from the Appropedia Wiki instructions. Note the "edit" hyperlink on the right hand side of the page. All of the instructions were editable by the teachers during the workshop.

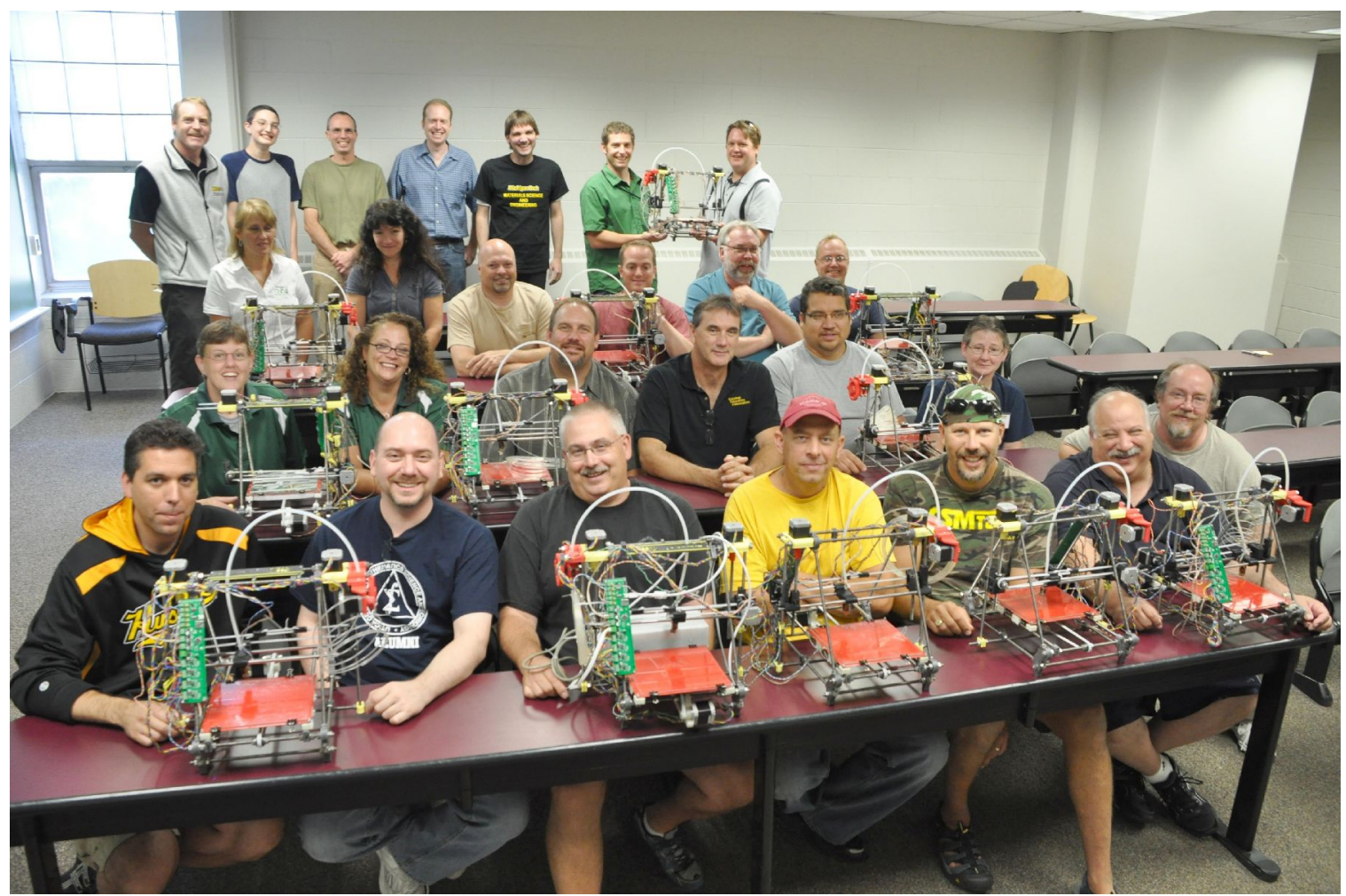

Figure 6: Group photograph of workshop participants (teachers and workshop facilitators) and their 3-D printers after a successful RepRap build. 